\section{Política y Sociedad}

ISSN-e: 1988-3129

https://dx.doi.org/10.5209/poso.71122

\title{
¿Gobernar los cambios del empleo en la revolución digital?
}

\author{
Fausto Miguélez ${ }^{1}$, Ramon Alós² y Oscar Molina ${ }^{3}$
}

Recibido: 14-08-2020 // Aceptado: 21-04-2021

Resumen. España está inmersa en plena revolución digital. Sus efectos cuantitativos sobre el empleo mantienen un elevado grado de incertidumbre, aunque sabemos que incidirá en eliminación de unos, creación de otros y transformación de muchos más. A partir de las opiniones de protagonistas en los actuales cambios (expertos, empresarios y sindicalistas) y de la literatura especializada, hemos repasado los principales retos que en un horizonte 2025 pueden afectar a España. Partiendo de los puntos débiles y los puntos fuertes del país respecto a la digitalización, hemos evaluado posibles políticas para mejorar la calidad y la cantidad del empleo. Para dar más consistencia al análisis, hemos estudiado las experiencias regulatorias de tres países europeos, Alemania, Francia y Reino Unido, para el caso de las economías de plataforma.

Palabras clave: empleo; revolución digital; economía digital; formación; sociedad; política; regulación; economía de plataforma.

\section{[en] Job regulation in the digital revolution?}

\begin{abstract}
Spain is in the midst of a digital revolution. The quantitative effects of the digital revolution on employment remain highly uncertain, although we know that it will be important in the elimination of some ones, the creation of others and the transformation of many more. Based on the opinions of the protagonists in the current changes (experts, employers and trade unionists) and on the specialized literature, we have reviewed the main challenges that may affect Spain until 2025. Taking into account the country's weaknesses and strengths with regard to digitalization, we have assessed possible policies aimed to improve the quality and quantity of employment. To give more consistency to our analysis, we have studied the regulatory experiences of three European countries, Germany, France and United Kingdom, in the case of platform economies.
\end{abstract}

Keywords: job; employment; digital revolution; digital economy; training; society; politics; regulation; platform economy.

Sumario. 1. Introducción: tecnología y sociedad. 2. Aproximación metodológica de esta investigación. 3. Los cambios que se pueden esperar en el trabajo. 4. Nuevas políticas para una nueva economía. 5. Las políticas que se aplican en algunos grandes países de la Unión Europea. 6. Conclusiones. 7. Bibliografía.

Como citar: Miguélez, F.; Alós, R. y Molina, O. (2021). ¿Gobernar los cambios del empleo en la revolución digital?. Polít. Soc. (Madr.) 58(3), 71122. https://dx.doi.org/10.5209/poso.71122

\section{Introducción: tecnología y sociedad ${ }^{4}$}

Las investigaciones sobre el tema que nos ocupa ponen de manifiesto que la revolución digital eliminará y creará empleos, y cambiará las características de muchos otros (Arntz et al., 2016; Nübler, 2016; Schwab, 2016; Doménech et al., 2018; Lladós, 2018; Eurofound, 2018a y 2019). La cuestión clave es, por lo que respecta a España, cuál podrá ser el resultado de este proceso dentro de algunos años (hemos planteado el horizonte de 2025). La Unión Europea (UE) presenta en 2010 (Comisión Europea, 2010a) una agenda digital europea que pretende ser la guía para las dos siguientes décadas. Los países de la UE replican esa guía; España lo hace tres años más tarde (Ministerio de Industria, 2013), seguida de sendos informes anuales para los años 2014 y 2015. Luego la agenda lleva una vida mortecina hasta 2018. Diversas investigaciones, entre otras Nübler (2016),

Universitat Autònoma de Barcelona (España)

E-mail: Fausto.Miguelez@uab.cat.

Universitat Autònoma de Barcelona (España)

E-mail: Ramon.dealos@uab.cat

Universitat Autònoma de Barcelona (España)

E-mail: Oscar.Molina@uab.cat

4 Este trabajo es un resumen del informe final del proyecto "Economía Digital y Políticas de Empleo", de los mismos autores, coordinado por Fausto Miguélez, y financiado por el Observatorio Social de la Caixa. Ver: Miguélez et al. (2019). 
McKinsey Global Institute (2017) y Eurofound (2019), indican que las repercusiones variarán por países en función de los niveles de cualificación de la fuerza de trabajo y de la posición del país en la cadena global de valor, lo que nos señala que el contexto de la economía global continuará teniendo peso. También se dará otro factor de variación: hemos tenido que enfrentarnos en 2020 a la pandemia Covid-19 - tanto en España como a nivel global - , lo que supondrá en el corto plazo una fuerte recesión, cuya duración no es fácil de calcular, y que puede acarrear una reorientación de la economía, que también será difícil de dibujar. En cualquier caso, la pandemia implicará cambios en la economía digital, positivos y negativos para el bienestar de los ciudadanos.

Estamos entrando en una nueva economía: la economía del conocimiento en palabras de unos (Powell y Snellman, 2004) o la economía digital en palabras de otros (Tapscott, 1996), según se ponga más el acento en las habilidades que serán centrales o en los instrumentos que acompañarán la actuación de los humanos tanto en el trabajo como en la vida cotidiana. Si bien es cierto que esa economía será en pocos años el eje vertebrador de todas las economías avanzadas (Schwab, 2016), no podemos olvidar que las condiciones en las que eso se dé pueden variar notablemente por países, por lo cual cabe dar entrada a otros factores explicativos de la transformación del empleo que pueden ser políticos, económicos, sociales y culturales. Además, como ha sucedido en fases anteriores del capitalismo, la nueva ola de innovación tecnológica convivirá durante mucho tiempo con las anteriores, contribuyendo a la segmentación de los mercados. Para captar mejor la complejidad en los modelos productivos actuales, es necesario no olvidarse de la globalización, que significa que las empresas pueden producir y vender bienes y servicios en países distintos; la digitalización ha incrementado esta posibilidad no solo para las empresas grandes (principalmente las multinacionales), sino también para las pequeñas y las medianas (PYMES), que digitalmente pueden operar en mercados diferentes de aquellos en los que tienen la sede social.

Pero la globalización también puede trastocar las posibilidades de actuación política ante las grandes transformaciones de la producción y del empleo, al debilitar el papel del Estado sobre la economía del país y, en ciertos casos, de su Banco Central. Habrá que mirar escenarios más amplios, en nuestro caso el escenario de la UE, sin perder de vista la necesidad de llegar a garantizar los derechos básicos — laborales, de salud, educativos-, así como ciertas obligaciones como fiscalidad, respeto ambiental y otros.

El artículo se estructura del siguiente modo: a continuación, se explica la aproximación metodológica llevada a cabo en la investigación; en el apartado 3 se abordan los principales cambios que se pueden esperar en el empleo en un próximo futuro; en el siguiente se analizan qué nuevas políticas pueden ser necesarias para una nueva economía; seguido, en el apartado 5, de una referencia a las políticas que ya se llevan a cabo en algunos grandes países de la UE. Finalmente, en las conclusiones, se resaltan los hallazgos más relevantes del proyecto, así como algunas reflexiones acerca de enseñanzas que se pueden derivar de la pandemia del Covid-19 en nuestro objeto de estudio.

\section{Aproximación metodológica de esta investigación}

Para llevar a cabo la investigación que sustenta este artículo, se siguieron varios pasos. Ante todo, se analizó la literatura existente sobre la temática objeto de estudio; esto es, las posibles repercusiones de la revolución digital en el empleo, en particular referidas a España; este primer paso nos puso en evidencia la diversidad de aproximaciones, así como de resultados obtenidos ${ }^{5}$. Esto nos permitió diseñar con precisión las preguntas de la investigación, en particular las referentes a los cambios del empleo en España, las posibles políticas dirigidas a conseguir que la revolución digital obtenga beneficios para la mayoría y las prácticas seguidas en otros países. Por lo que se refiere a los aspectos empíricos, señalamos, en primer lugar, los materiales elaborados por instituciones de diversa índole, desde gubernamentales, a organizaciones especializadas, organizaciones empresariales y sindicatos; material que en su conjunto ha servido para conocer diversos puntos de vista, así como medidas concretas que han sido adoptadas o bien se proponen. En segundo lugar, se llevó a cabo una recopilación de datos estadísticos que permitieran situar y valorar el objeto de estudio, datos procedentes de organismos públicos, pero asimismo a partir de cuestionarios llevados a cabo por organizaciones especializadas.

En tercer lugar, a partir de entrevistas mantenidas con diez expertos (académicos y con personas reconocidas en el campo de las tecnologías y el empleo), se confeccionó una relación de personas conocedoras del mercado de trabajo, empresarios de grandes y pequeñas empresas innovadoras, y sindicalistas, todos ellos de España. A estos se les pasó un cuestionario estructurado al que debían responder aportando sus opiniones con respecto al futuro del empleo, en un horizonte 2025, como consecuencia de la revolución digital, así como sobre las principales actuaciones que consideraban deberían adoptarse, siempre en referencia a España. Se trata de una aproximación exploratoria a partir de un cuestionario dirigido a personas que, desde diversos puntos de vista, tendrán que ver en el devenir del mercado de trabajo. Para ello un aspecto fundamental ha sido dar prioridad a la diversidad de posiciones, de conocimientos y de ámbitos de intervención de unos y otros. Finalmente, de un total de 197 personas contactadas, hemos obtenidos 89 respuestas válidas. Por colectivos son los siguientes: de expertos, básicamente académicos (economistas, sociólogos, juristas...), 41 respuestas de 92

Para mayor detalle, véase Miguélez (2019). 
contactados (44,56\% de respuesta); de empresarios, 24 respuestas de 67 contactados $(35,82 \%$ de respuesta); de sindicalistas, 24 respuestas de 38 contactados (63,15\% de respuesta). La recogida de las respuestas se llevó a cabo entre los meses de setiembre y diciembre de 2018. Por supuesto, los resultados de un cuestionario de este tipo no son estadísticamente representativos de un determinado universo, sino que se acercan a la función que tienen las entrevistas estructuradas, con la ventaja de que el número de respuestas es más elevado que si se tratara de entrevistas y su resultado fácil de ser representado gráficamente. Así, con el cuestionario no se ha buscado representatividad estadística, sino obtener opiniones de personas cualificadas, que conocen bien el tema y/o actúan en su vertiente práctica.

Finalmente, se ha llevado a cabo una comparación de España con algunos países de la UE, específicamente Alemania, Francia y Reino Unido; este análisis se ha acotado a las experiencias regulatorias en dichos países para el caso de las economías de plataforma. Su objetivo ha sido ver el modelo preponderante en cada país para organizar socialmente la nueva economía, particularmente en el campo del empleo.

\section{Los cambios que se pueden esperar en el trabajo}

La complejidad de un ejercicio prospectivo como este salta a la luz si observamos la gran disparidad de resultados de dos de las investigaciones posiblemente más emblemáticas al respecto: mientras que para Frey y Osborne (2015) el 43\% de los puestos de trabajo en España estarían en riesgo elevado de ser automatizados a medio plazo, Arntz et al. (2016) reducen ese riesgo al 12\%, si bien otro $20 \%$ sería susceptible de una automatización parcial. Más allá de unas y otras previsiones, como nos recuerda Nübler (2016), hasta el momento no se ha dado una relación fuerte entre aumento en la robotización o la digitalización y reducciones de empleo, lo que significa que se ha creado empleo en ciertos sectores.

Las investigaciones específicas sobre España, la realizada por nosotros y otras que hemos tenido en cuenta señalan que hasta ahora se han aprovechado poco las posibilidades de avanzar hacia una economía y sociedad del conocimiento que pudiera ser beneficiosa en términos de empleo y también de bienestar, dirigiendo los resultados de la digitalización a una razonable redistribución de la riqueza creada. En comparación con el resto de países de la UE, constatamos que España está en una posición por encima de la media por lo que respecta a conexiones digitales y a la e-administración. Sin embargo, está por debajo de dicha media en el uso de internet, en capacidades digitales, en particular aquellas más avanzadas - lo que, además, se acompaña con una brecha de género, de edad y territorial-y también está por debajo en inserción de las PYMES en la economía digital (European Commission, 2020).

¿Qué efectos de la digitalización son esperables sobre el empleo? Podríamos pensar que la destrucción de empleo será notable, debido a la baja cualificación de muchos trabajos. Pero también sería posible que la precarización del empleo y los bajos salarios retardasen ese efecto; algo que no nos libera de la amenaza, sino que nos da más tiempo para prepararnos. Debido a esta ambivalencia, hemos planteado en el cuestionario una pregunta abierta sobre puntos débiles y puntos fuertes de la economía española ante la digitalización. Los puntos débiles referidos son, por orden (ver gráfico 1): el modelo productivo (baja inversión en $\mathrm{I}+\mathrm{D}+\mathrm{i}$, sectores poco innovadores, tamaño empresarial pequeño, cultura empresarial poco innovadora), el sistema educativo que prepara insuficientemente para el cambio y las nuevas cualificaciones y habilidades requeridas, políticas públicas débiles, formación continua poco extendida y poco consistente. Frente a ello, como puntos fuertes se señalan (ver gráfico 2): la adaptabilidad de los jóvenes y la buena formación en ingenierías, el atractivo inversor del país, la consistencia de las infraestructuras digitales, la e-administración. Los puntos fuertes, con alguna excepción, son mayoritariamente pasivos o de condiciones contextuales; no aparecen entre los mismos referencias al dinamismo empresarial.

Gráfico 1. Principales puntos débiles de España ante la digitalización (en \% de distribución respuestas) $(\mathrm{N}=234)$

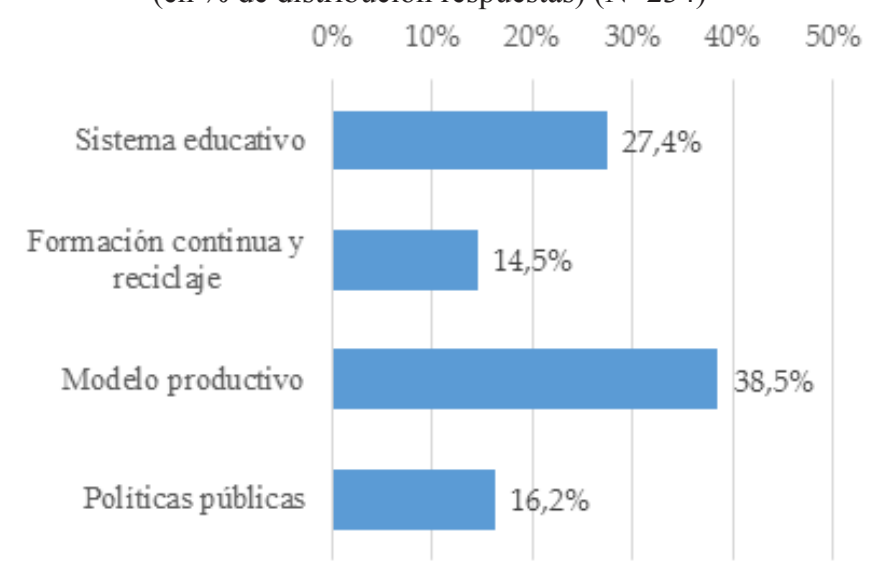

Nota: las personas encuestadas podían señalar hasta 3 respuestas. Fuente: Miguélez et al. (2019). 
Gráfico 2. Principales puntos fuertes de España ante la digitalización (en \% de distribución respuestas) $(\mathrm{N}=164)$

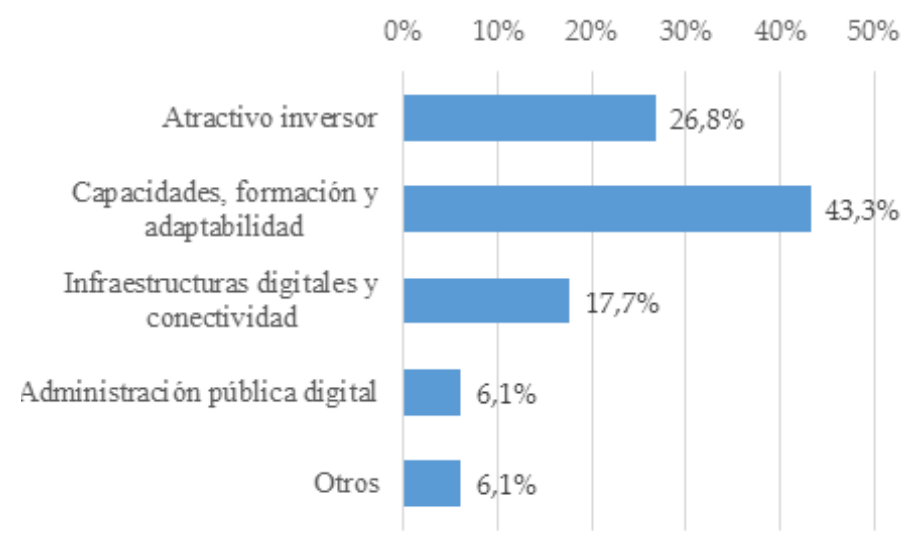

Nota: las personas encuestadas podían señalar hasta 3 respuestas.

Fuente: Miguélez et al. (2019).

Más allá de su cuantificación, en el aspecto en el que se da una mayor coincidencia en los estudios realizados con respecto al futuro del empleo es en que este experimentará importantes cambios; esto es, se alterará su composición sectorial y de las ocupaciones, habrá cambios en las tareas y en los requerimientos formativos y profesionales, así como en las condiciones de su ejecución contractual, de espacio o lugar, tiempo, etc.

Nos hemos interesado en saber cuáles pueden ser las habilidades transversales más exigidas para el próximo futuro, además de dar por supuesta la necesidad de las habilidades STEM (ciencias, tecnología, ingeniería y matemáticas, según sus siglas en inglés). Creatividad, capacidad de resolución de problemas complejos, flexibilidad cognitiva, trabajo en grupo son las que reciben más menciones, aunque ninguna lo es por más del $50 \%$ de los entrevistados (ver gráfico 3). Otras investigaciones (Adecco, 2016; McKinsey Global Institute, 2017) ponen también el acento en esta transversalidad.

Gráfico 3. ¿Qué competencias transversales cree que serán las más buscadas, de la siguiente lista en los próximos años (perspectiva 2025)? $(\mathrm{N}=258)$

$\begin{array}{llllllllllllllllllllll}0 \% & 5 \% & 10 \% & 15 \% & 20 \% & 25 \% & 30 \% & 35 \% & 40 \% & 45 \% & 50 \%\end{array}$

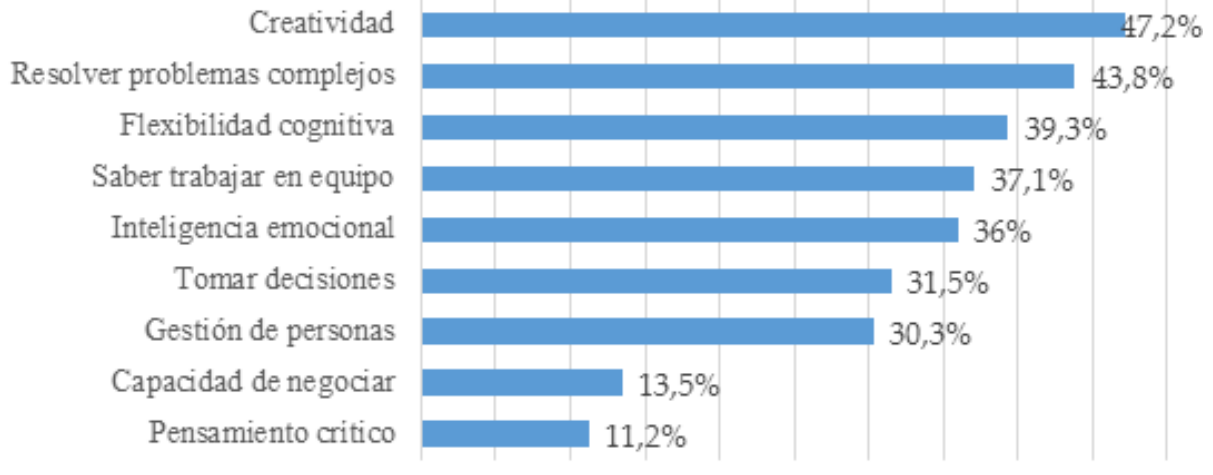

Nota: las personas encuestadas podían señalar hasta 3 respuestas Fuente: Miguélez et al. (2019).

Las plataformas digitales como formas organizativas empresariales parecen ser determinantes del estatus y de las condiciones de muchos empleos (Todolí, 2015); específicamente, que dichos empleos tengan la categoría de trabajador "independiente" o por proyecto. Mientras los Estados no regulen su actividad, las plataformas digitales son las que fijan las condiciones bajo las cuales se presta el servicio, con unas condiciones de empleo, de representación y de protección social que en el mejor de los casos son poco claras, cuando no decididamente desfavorables para quienes trabajan para ellas respecto a otros trabajadores del mismo sector en empresas "convencionales" (De Stefano, 2016; Eurofound, 2018b; Pesole et al., 2018). No es de extrañar, pues, que cada vez resulte más habitual asociarlas con bajas remuneraciones, condiciones de empleo precarias y con el rechazo de unas relaciones laborales normalizadas (Drahokoupul y Fabo, 2016; Eurofound, 2018a y 2018b), a la vez que suponen un serio reto para el diálogo social (Rocha y de la Fuente, 2018). Los encuestados confirman estos pronósticos, pues mayoritariamente se decantan por señalar que este fenómeno tenderá a incrementarse y que ello aumentará la precariedad, sea de la relación laboral o de las condiciones de dichos empleos. Soete (2018) destaca que mientras la digitalización favorece la fluidez de los mercados y la facilidad de entrada, también au- 
menta de forma perceptible la dependencia de las sociedades con respecto a las plataformas digitales globales, como son Google, Facebook o Amazon, siendo una de sus consecuencias un mercado más monopolístico, para el que el autor acuña el término de "capitalismo monopolista digital".

La estructura del empleo en España empieza a cambiar bajo la influencia de las nuevas tecnologías, pero los cambios siguen condicionados por la posición en la división internacional del trabajo, el marco institucional y regulatorio, así como por las políticas que se han desarrollado o no se han derogado en los últimos años; es decir, recortes muy fuertes en servicios públicos y prácticas neoliberales en la gestión de la mano de obra en las empresas, con un elevadísimo uso de la contratación temporal, que además es de muy breve duración (Lladós, 2018). Con todo, hay indicios de que las cosas pueden cambiar en los próximos años si se aplicaran políticas diferentes.

En nuestro estudio las personas encuestadas optan muy mayoritariamente (hasta un 69,7\%) por la tesis de que la digitalización dualizará más el empleo, siendo solo un $19,1 \%$ los que opinan que el empleo será más homogéneo y mejorará su calidad, mientras para un $11,2 \%$ no se darán cambios sustantivos. Los empresarios se decantan más por considerar que con la digitalización mejorará la calidad del conjunto del empleo, al exigir unas habilidades que mucha gente podrá adquirir, mientras expertos y sobre todo sindicalistas resaltan muy mayoritariamente que la digitalización dualizará más el empleo.

Con la revolución digital, las personas se enfrentan ante los retos de una adaptación constante a entornos laborales nuevos, a cambios en ocupaciones y en tareas, a la elección de nueva formación y aprendizajes a lo largo de la vida laboral y a diferentes, y no siempre previsibles, itinerarios ocupacionales y profesionales (European Commission, 2019). Por ello uno de los interrogantes sobre la digitalización y el futuro del empleo que más consenso genera se refiere al papel clave de la educación-formación y cómo se debe adaptar el sistema educativo, el reciclaje y la formación a lo largo de la vida, la formación continua y el lugar que deben ocupar las STEM (Accenture y MWCB, 2017; CEOE, 2016; CES, 2017; Lope, 2018; PWC, 2018). Y, también, de acuerdo con Nübler (2016), cómo preparar y qué instituciones son necesarias para generar la base del conocimiento y capacidades que permitan que la economía genere nuevos empleos en nuevas actividades.

Como señalan López-Sintas et al. (2018), muchas de las competencias que requieren los nuevos empleos se adquieren en la experiencia cotidiana en el trabajo, no solo en la enseñanza reglada. Por eso convendrá evitar que, a pesar de existir una oferta de trabajo abundante y bien formada en competencias genéricas, sea escasa en competencias específicas; este es un aspecto que remite a la formación continua, en la que las empresas deben asumir un mayor protagonismo y asimismo responsabilidad, pues actualmente está en niveles unánimemente considerados muy bajos (Lope, 2018; Planas, 2018).

\section{Nuevas políticas para una nueva economía}

La política es unas de las respuestas claves a la revolución tecnológica, política que debería tener un carácter más proactivo que reactivo, no esperar, como sucedió en otras revoluciones tecnológicas, a que las nuevas tecnologías estén sólidamente implantadas para intervenir. La Administración puede contar también con un ingente volumen de datos públicos y privados (big data) y es capaz de realizar múltiples previsiones sobre la incidencia de las nuevas tecnologías por lo que se refiere a la evolución del empleo, a las necesidades educativas y de formación, a las necesidades de las empresas, a la evolución demográfica, a la problemática ecológica, etc. Por tanto, no se trata de esperar al momento en que las empresas consoliden sus tecnologías productivas; la digitalización proporciona a la Administración, a los actores políticos y sociales y a los ciudadanos instrumentos nuevos para intervenir en el cambio mismo.

Otro de los aspectos que deberían ser tenidos en cuenta es que los procesos a los que nos referimos tienen una vertiente global tan incuestionable como lo es hoy el sistema económico, lo cual convierte en insuficientes determinadas respuestas políticas del país si no van acompañadas por cambios a nivel supraestatal, ante todo europeo. Cabe pensar, al respecto, en políticas demográficas, políticas de $\mathrm{I}+\mathrm{D}+\mathrm{i}$, políticas fiscales, dada la presencia de las empresas en varios países de la UE. Pero, hoy por hoy, el primer motor siguen siendo las políticas nacionales. Las instituciones y los ciudadanos también deben ser involucrados en estos procesos de diseño e implementación de políticas. Por supuesto, se tendrá que tener en cuenta lo que pasa en otros países, en particular en aquellos que pueden ser más afines al nuestro, y que pueden actuar como modelos, así como los avances que se den en la UE.

Nos referiremos, en primer lugar, al campo que podríamos llamar de "adaptación" de la revolución digital a las necesidades de la población y del conjunto de las empresas, una adaptación en la que las políticas de los países tienen un peso importante; es decir, además de las estrategias tecnológicas de las empresas, que son capitales, tenemos la actuación de la Administración con inversiones y regulaciones. A tal respecto, una de las constataciones más relevantes es que aún estamos muy lejos de lo que la UE plantea como ideal en inversión en I+D+i para 2020, el 3\% del PIB; la media de la UE está en 2,12\% en 2018 y España en el 1,24\%, muy por debajo de la media de los 27 países. La Comisión Europea insta a que los Estados miembros hagan un esfuerzo suplementario en inversión pública, que podría y debería estar priorizada hacia determinados sectores y objetivos (Comisión Europea, 2010b). El reto es muy importante, pero es ahora cuando se debe dar el gran salto, 
fortaleciendo la investigación en la universidad, la colaboración público-privado, las infraestructuras digitales en general, la modernización de infraestructuras sanitarias y educativas.

Tabla 1. Inversión en $\mathrm{I}+\mathrm{D}+\mathrm{i}$ de 2009 a 2018 en algunos países de la UE

\begin{tabular}{|l|c|c|c|c|c|}
\hline & $\mathbf{2 0 0 9}$ & $\mathbf{2 0 1 0}$ & $\mathbf{2 0 1 5}$ & $\mathbf{2 0 1 6}$ & $\mathbf{2 0 1 8}$ \\
\hline EU (28 países) & 1,93 & 1,93 & 2,03 & 2,04 & $2,12(\mathrm{p})$ \\
\hline Alemania & 2,72 & 2,71 & 2,92 & 2,92 & $3,13(\mathrm{p})$ \\
\hline Austria & 2,60 & 2,73 & 3,05 & 3,13 & $3,17(\mathrm{p})$ \\
\hline Bélgica & 1,99 & 2,05 & 2,47 & 2,55 & $2,78(\mathrm{p})$ \\
\hline Dinamarca & 3,06 & 2,92 & 2,96 & 3,12 & $3,03(\mathrm{p})$ \\
\hline España & 1,35 & 1,35 & 1,22 & 1,19 & $1,24(\mathrm{p})$ \\
\hline Finlandia & 3,75 & 3,73 & 2,90 & 2,74 & 2,75 \\
\hline Francia & 2,05 & 2,21 & 2,23 & 2,22 & $2,20(\mathrm{p})$ \\
\hline Grecia & 0,63 & 0,60 & 0,97 & 0,99 & $1,18(\mathrm{p})$ \\
\hline Irlanda & 1,61 & 1,59 & 1,20 & 1,19 & 1,15 \\
\hline Italia & 1,22 & 1,22 & 1,34 & 1,37 & $1,39(\mathrm{p})$ \\
\hline Países Bajos & 1,69 & 1,72 & 1,98 & 2,00 & $2,12(\mathrm{p})$ \\
\hline Polonia & 0,66 & 0,72 & 1,00 & 0,96 & $1,21(\mathrm{p})$ \\
\hline Portugal & 1,58 & 1,53 & 1,24 & 1,28 & $1,35(\mathrm{p})$ \\
\hline Suecia & 3,45 & 3,22 & 3,27 & 3,25 & $3,31(\mathrm{p})$ \\
\hline
\end{tabular}

Nota: $(\mathrm{p})=$ datos provisionales

Fuente: Eurostat 2020.

Hay países de la UE que durante la crisis financiera iniciada en 2008 han aumentado su apuesta por el $\mathrm{I}+\mathrm{D}+\mathrm{i}$, posiblemente como estrategia para posicionarse mejor después de la crisis; otros que se han mantenido en posiciones altas y otros que no han despegado de posiciones bajas o hasta han descendido durante la década, lo que reflejan los datos señalados. Entre estos últimos se encuentra España que, partiendo de posiciones bajas, ha caído aún más y solo en 2018 parece haber frenado esa tendencia; sin duda aumentar esta inversión es uno de los principales retos de futuro a los que se enfrenta la economía española. Al mismo tiempo, los datos ponen de manifiesto no solo que se mantienen grandes diferencias entre países, sino también que la pertenencia a la UE no es un factor determinante para poder llegar a los objetivos que la Comisión Europea manifiesta en relación a 2020.

Un cambio de la economía beneficioso para la sociedad no va a depender solo de las nuevas tecnologías, sino también del modelo energético, en particular porque esto tendrá en cuenta el reto de la crisis climática. En consumo de energía de fuentes renovables, España, en puestos muy avanzados hasta 2008, muestra una posición muy retrasada en 2018. En otras palabras, podemos hablar de una década perdida y que hace prácticamente imposible alcanzar los objetivos marcados para 2020.

Pero lo más llamativo es que entre 2012 y 2016 la UE, de media, ha incrementado su inversión en energías renovables en el 23,3\%, mientras que España solo lo ha hecho en el 3,4\% (IRENA, 2017). Por tanto, los avances son muy limitados en capítulos esenciales para un futuro de fuerte innovación tecnológica con salvaguarda medioambiental. Parece que el papel de los poderes públicos en este aspecto tiene que ser fundamental, sea a través de la inversión directa o en colaboración, sea a través de políticas fiscales en el tema energético. No cabe olvidar los decisivos apoyos públicos que los Estados han dado a la energía fósil, fundamental en los últimos 100 años de desarrollo económico. Alguna investigación reciente ha cifrado en el 6,5\% del PIB mundial los subsidios públicos en 2015 a dicha energía (Coady et al., 2017). Por tanto, tiene poco sentido oponerse a subsidiar las energías renovables, algo que España realizaba con el gobierno socialista hasta 2011.

Una atención especial debe ser dirigida a apoyar las PYMES, tanto en cuanto a innovación tecnológica, como en otros aspectos organizativos y fiscales, puesto que suponen más del $95 \%$ de las empresas de este país. Las PYMES están retrasadas en la utilización de instrumentos digitales para poder competir con otras empresas, en muchos casos no ya en el propio país, sino en Europa o en la economía global a través de compras y ventas online, computación en la nube, nuevas formas organizativas, etc. (CES, 2017). Nuestra investigación pone de manifiesto que, si bien puede ser importante que las PYMES tengan facilidades de acceso al crédito (lo piensan el 52,8\% de los entrevistados), también lo es la formación y el cambio de mentalidad de los empresarios y dirigentes de estas empresas $(22,5 \%)$; y, asimismo, el apoyo a la contratación de profesionales con competencias digitales por PYMES (16,9\%), algo que podría relacionarse con un nuevo diseño de políticas activas que facilitase la acumulación e incorporación de trabajadores con competencias digitales en las PYMES.

La Administración Pública puede impulsar otras funciones para lograr la modernización de la estructura productiva ante la revolución digital, además de cambios en el empleo de los servicios públicos y en la contra- 
tación con empresas privadas. El gráfico 4 muestra algunas de estas medidas según los resultados del estudio realizado.

Gráfico 4. Papel de la Administración en la modernización ante la revolución digital y otros cambios $(\mathrm{N}=164)$

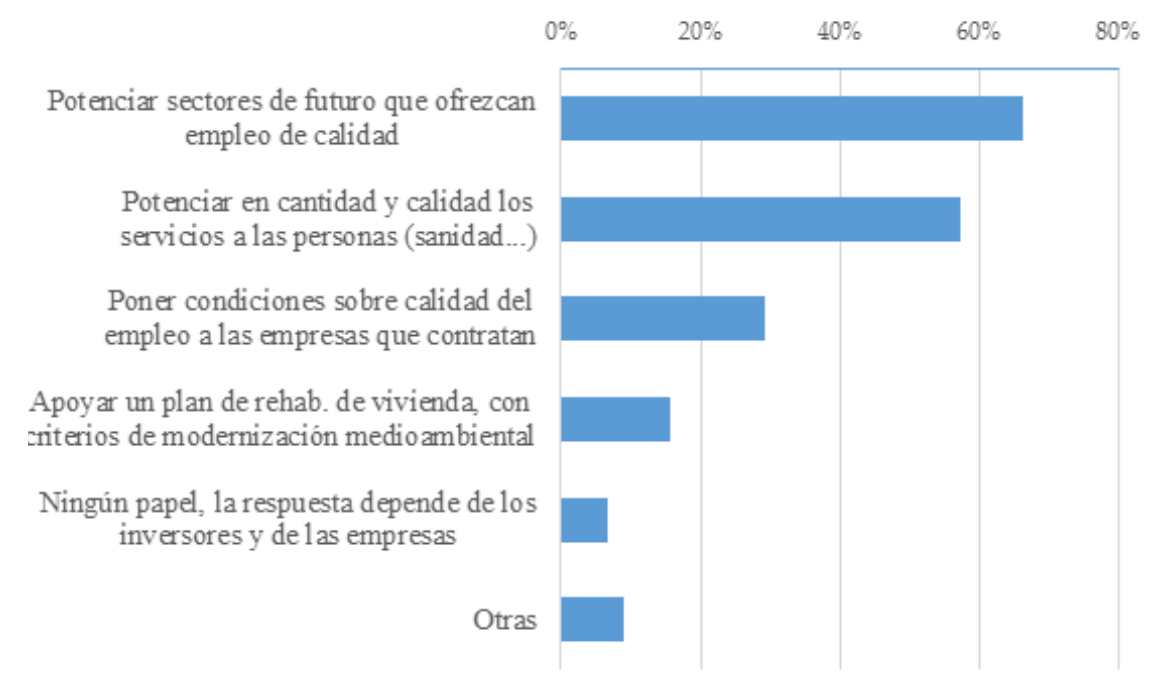

Fuente: Miguélez et al. (2019).

Potenciar sectores de futuro, con especial atención a los digitales, parece ser el ámbito más relevante; una corriente de economistas está volviendo a reivindicar el papel determinante del Estado, en particular cuando aparece una crisis (Mazzucato y Semieniuk, 2017), siempre que esta intervención tenga objetivos claros y transparentes. Pero también en la modernización de los servicios, en la contratación de infraestructuras y en la rehabilitación de la vivienda con criterios medioambientales, las políticas pueden dar un impulso al empleo de calidad, que contrarreste las pérdidas que se den en otros sectores, sin que ello suponga que las empresas privadas no jueguen un papel importante en este proceso.

En segundo lugar, está el campo de la adecuación de la fuerza de trabajo a los nuevos requisitos de la actividad económica, puesto que la revolución digital requiere contar con mano de obra adecuada (Nübler, 2016). Adquiere una especial relevancia la educación-formación.

Gráfico 5. Los cambios que la nueva etapa económica requiere en la educación inicial (N=169)

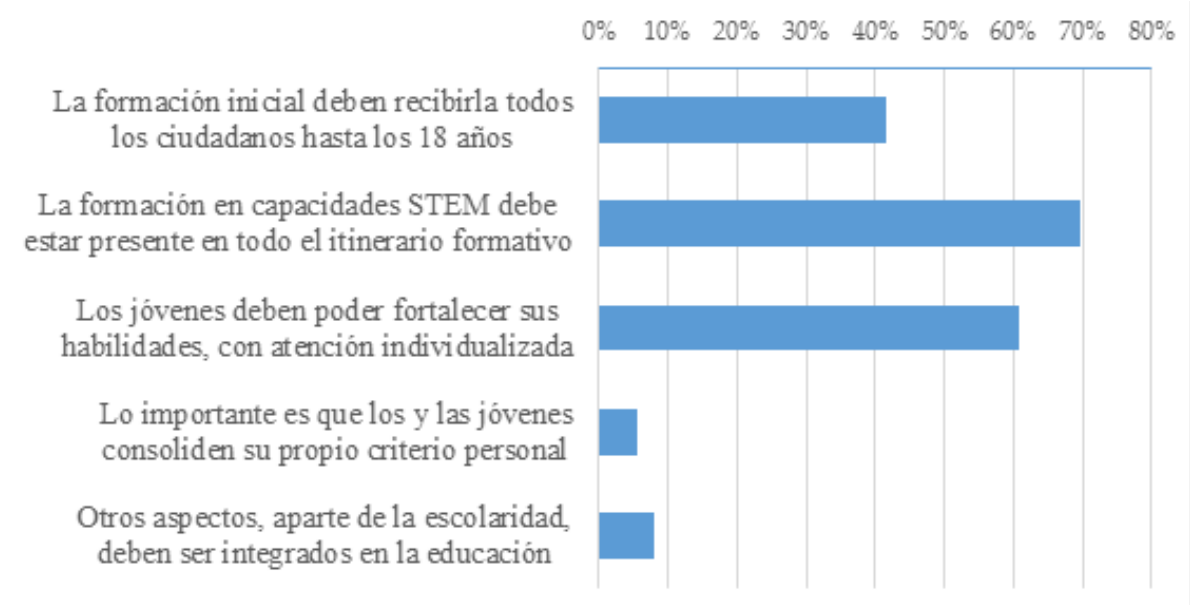

Fuente: Miguélez et al. (2019).

La conclusión más contundente que arroja la encuesta es que esa educación-formación debe empezar a los 3 años y continuar, al menos, hasta la edad de jubilación (gráfico 5). Quienes responden al cuestionario tienen claro que las habilidades STEM han de tener un papel importante en el modelo educativo, pero casi tanta importancia atribuyen a que los jóvenes fortalezcan sus habilidades individuales, que pueden ser digitales, artísticas, de relación social, etc., algo que subrayan muchos expertos como la mejor forma de potenciar las capacidades de cada persona (Planas 2018). La razón es que esas habilidades son claves para la empleabilidad en el contexto actual y futuro, más allá del proceso de inserción en el mercado de 
trabajo. Estas habilidades asientan las bases para ir adquiriendo nuevas competencias a medida que los cambios tecnológicos las requieran, teniendo en cuenta también la necesidad de estar preparados para la presumible gran expansión de internet en la vida cotidiana ${ }^{6}$ como ciudadanos que desean beneficiarse plenamente de las nuevas posibilidades, en términos de condiciones de vida, además del empleo. Por ello, no se trata únicamente de adquirir habilidades digitales, probablemente cada vez más complejas; se trata también de desarrollar nuevas actitudes, nuevas pautas comunicativas, nuevas formas de relación social, nuevas maneras de apreciar los bienes culturales.

En cualquier caso, es muy mayoritaria la respuesta al cuestionario que señala que la Administración debe incentivar a los ciudadanos para que adquieran nuevas habilidades, tanto en el trabajo como fuera del mismo, en lo que los expertos llaman "educación a lo largo de la vida" (ELV). Por ello, parecería adecuado que esta exigencia se reflejara en los convenios colectivos, en los presupuestos de los Ministerios de Educación y de Trabajo y de las consejerías autonómicas de esos ramos, en los planes de las instituciones docentes y en las previsiones de las empresas. Los organismos internacionales están hablando de la formación a lo largo de la vida como de un derecho (OIT, 2019). El trabajador que no se forma de manera continua es un trabajador que pierde habilidades y oportunidades.

Para revertir esta situación es necesario acompañar los incentivos públicos con cambios que mejoren las expectativas tanto de los trabajadores como de las empresas. Por ejemplo, un trabajador no tiene mucho interés en formarse si su contrato es de meses o semanas y se ve obligado a saltar de empresa o de sector. Aquí radica uno de los grandes males de nuestro modelo de empleo, y así deberían entenderlo los empresarios. Mención aparte merece la formación ocupacional, eje hoy fundamental de las políticas activas, que debería ser mejorada y, según muchos expertos, gestionada más descentralizadamente para incrementar su eficacia (Navarro, 2018).

También conviene tener en cuenta las posibles nuevas regulaciones con el fin de preservar los derechos de los trabajadores para una relación laboral segura, para la acción colectiva y para negociar sus condiciones laborales. Las formas de vinculación con las empresas están cambiando aceleradamente. Esto será difícil evitarlo, pero ello no quiere decir que las nuevas relaciones no puedan tener garantías de defensa de ciertos estándares por parte de la Administración (leyes, inspecciones, tribunales), que debe velar por el bienestar de todos. Particularmente disruptiva y preocupante es la expansión de la figura de trabajador "independiente". En este sentido, los sindicatos (CCOO, 2017; UGT, 2018) subrayan la necesidad de que nadie pierda el derecho a la negociación colectiva, mientras que la patronal (CEOE, 2016) señala la necesidad del diálogo social. No parece mal comienzo si no se queda solo en palabras.

Los sindicatos deberán activarse en este campo, si quieren seguir representando a todos los trabajadores. Quienes contestan el cuestionario, sean sindicalistas o expertos y empresarios, tienen muy claro que las nuevas condiciones que garanticen derechos laborales básicos han de ser reguladas, tanto directamente en el Parlamento, como a través de los representantes de los ciudadanos después de un acuerdo conseguido mediante el diálogo social. De ninguna manera en la economía digital deben determinar unilateralmente las empresas cómo se trabaja.

Finalmente, en el campo de las políticas contra el desempleo y el mal empleo (sea este en términos de seguridad contractual como de salario o jornada), los resultados muestran una percepción positiva y necesaria de la reducción del tiempo de trabajo, pero sin que comporte una disminución grave de los salarios, co una forma de garantizar empleo para todos (ver gráfico 6).

Hay dos argumentos que refuerzan sobradamente este cambio radical. El primero se refiere a que las tecnologías digitales serán, en la mayoría de actividades, generadoras de riqueza con menos trabajo que en el pasado; por tanto, la cuestión no es solo cuánta riqueza se crea, sino también cómo se reparte; es decir, no es una cuestión económico-tecnológica, sino de relación social. El segundo se refiere a que más tiempo de no trabajo generará dos potenciales beneficios muy importantes: uno será directamente para las personas afectadas, puesto que posibilitará una mejor distribución de las tareas domésticas y de cuidado, permitirá a las madres y padres dedicarse durante un largo tiempo a los nuevos nacidos y dejará tiempo para la formación y para las actividades culturales, de ocio y de amistad. El otro tiene que ver con la colectividad, puesto que el tiempo libre será una gran bolsa de nuevos empleos para satisfacer esas nuevas necesidades de los ciudadanos, por ejemplo, en términos de actividades culturales y de ocio.

Con todo, seguirá habiendo un elevado desempleo, tanto por un cambio estructural muy rápido —el desempleo estructural ya ha crecido en los últimos años-, como porque a muchas personas les costará adaptarse o, sencillamente, no estarán de acuerdo en seguir ese ritmo, lo que generará más desigualdades. Desde hace tiempo varios expertos y numerosas experiencias (Sarasa, 2018) están planteando que la Administración debe asegurar unos ingresos mínimos, ya sea en forma de una renta mínima garantizada para quien no disponga de ingresos o ingresos suficientes, o una renta universal garantizada, incondicional e indefinida. Mayoritariamente, los entrevistados se decantan por una renta garantizada para desempleados y para quienes tengan ingresos claramente insuficientes, condicionada a algún tipo de trabajo público o mecanismo de posible acceso a un em-

En referencia a la comunicación, a la movilidad, a la vivienda, al tiempo libre, a las actividades culturales, a las formas de viajar y un largo etcétera. 
pleo en el mercado, como es la formación, por más que una minoría significativa apuesta por la otra fórmula. En esta línea de no universalidad y condicionalidad se sitúa el recién aprobado ingreso mínimo vital en España, que quiere hacer frente al imponente crecimiento de la pobreza que la Covid-19 ha acentuado 7 .

Es un debate de envergadura, que en el fondo relaciona el derecho al trabajo digno con el derecho a vivir dignamente. Como señalan algunos autores, la renta de subsistencia condicionada es una propuesta que se basa en el convencimiento de que el trabajo es un derecho porque garantiza derechos, dado que contribuye a la creación de riqueza (Prieto y Alaluf, 2018), mientras que la renta incondicional solo garantiza el derecho a subsistir. Ello nos lleva también a adecuar las políticas activas a la nueva situación, remodelándolas a fondo en dos aspectos: por un lado, en la formación que se recibe, en contenidos, quién la imparte, cuál es el papel de las empresas; por otro lado, en la gestión de dichas políticas, al acercarlas mucho más al territorio, con el mismo derecho con el que se vinculan las políticas sociales y culturales al territorio, y dotándolas de recursos y técnicos suficientes.

Gráfico 6. ¿Reducción de la jornada laboral para paliar la reducción de empleos? (N=89)

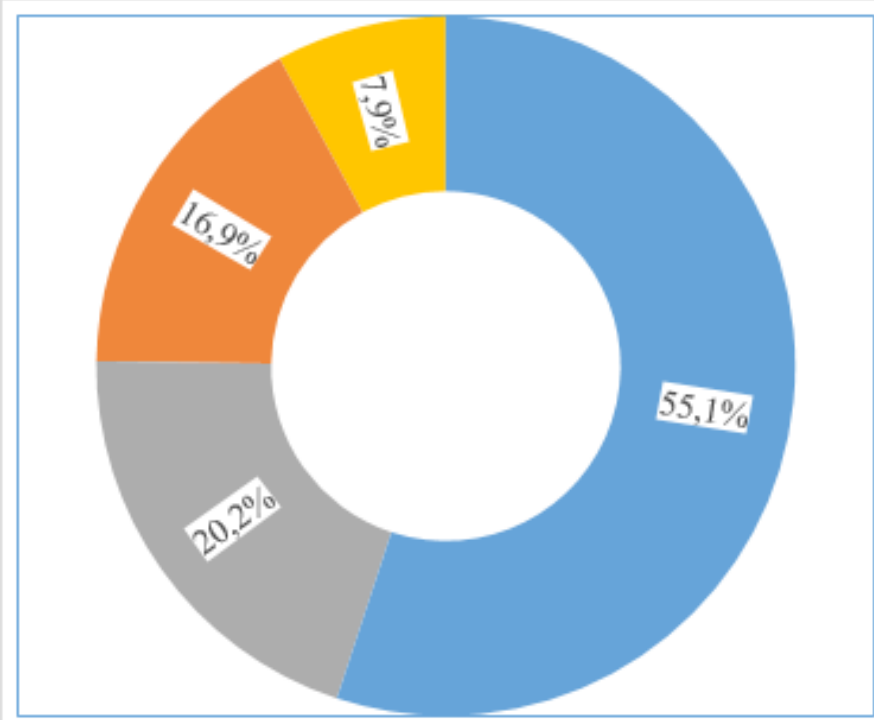

Deberíamos trabajar todos,

reduciendo la jornada pero no el salario.

Deberíamos trabajar todos, - reduciendo la jornada y también el salario.

Quienes trabajan y quienes

no debería depender de las necesidades del mercado.

\section{NS/NC}

Fuente: Miguélez et al. (2019).

\section{Las políticas que se aplican en algunos grandes países de la UE}

Una última cuestión que hemos querido abordar es la respuesta regulatoria-política que en otros países de la UE - hemos escogido Alemania, Francia y Reino Unido - se está dando a la revolución digital en su vertiente económico-productiva. De las múltiples manifestaciones de la economía digital, nos hemos centrado en las organizaciones productivas que probablemente son más significativas en el momento actual, la llamada economía de plataforma, dada su repercusión tanto sobre el empleo como sobre la competencia y, en algún grado, sobre el modelo fiscal existente. De alguna manera, el caso de la economía de plataforma es paradigmático de las transformaciones en curso y sus implicaciones, de ahí la importancia de su análisis.

Cabría preguntarse por qué puede ser adecuado regular específicamente el empleo y el mercado de trabajo en esta fase del cambio tecnológico. Si somos sensibles a lo que señalan diversas investigaciones recientes (Dittrich, 2018; Rauch y Schleicher, 2015; Maselli et al., 2016), tres son los motivos que parecen requerir regulación: deterioro de derechos laborales, la competencia desleal ejercida por parte de las plataformas y el impacto negativo que puede tener en los sistemas fiscales. Pero es un tema controvertido, también hay autores que creen que el mejor regulador sería simplemente la dinámica del mercado, $u$ otros que piensan que la rapidez del cambio tecnológico es tan vertiginosa que la regulación siempre llegará tarde (ver al respecto Allen y Berg, 2014; Berg y De Stefano, 2016). También suscita controversia el marco de la regulación. La UE ha avanzado en regulaciones supranacionales que afectan a derechos de las personas (por ejemplo, la privacidad en las actividades digitales) o bien en el ámbito de la competencia; pero apenas ha entrado en derechos sociales, área en la que se ha movido un poco la regulación en algunos países. Sin embargo, siguiendo la estela de algunas propuestas de la Comisión Europea, como la Agenda Digital para Europa (Comisión Europea, 2010a) y el Mercado Único Digital (Comisión Europea, 2015), tendría sentido que la UE regulara para los 27 socios, dado 
que es evidente que hemos entrado en una fase del cambio tecnológico que es esencialmente supranacional; con competitividad supranacional y mercado de trabajo, en ciertos ámbitos, también supranacional.

En términos generales, los Gobiernos han sido poco proclives a entrar en regulaciones que tienen que ver con el mercado de trabajo, que es el aspecto específico que en esta investigación hemos tenido en cuenta. Se han movido en otros aspectos y han tenido tres características principales. En primer lugar, las respuestas de los Gobiernos a la economía digital y de plataforma son generalmente de alcance limitado, reactivas ante efectos concretos - estatus y cobertura legal de los nuevos trabajadores, enfrentamientos por nuevas formas de competitividad-, pero no se está trabajando, más proactivamente, en un nuevo marco general para el desarrollo de la economía digital que limite sus efectos sociales potencialmente negativos sin menoscabar su capacidad para generar innovación y riqueza (Lenaerts et al., 2017). En segundo lugar, la incorporación de la economía digital y de plataforma a la agenda pública ha venido en general determinada por los efectos de algunas empresas que han encontrado oposición en determinados colectivos. Este es en particular el caso de Uber, que ha encontrado fuerte oposición por parte de los taxistas. Es decir, son actuaciones que se han dado como respuesta a movimientos de aquellos que han sufrido la nueva organización productiva: taxistas, riders, nuevos trabajadores independientes, proliferación de falsos autónomos, aunque se han registrado también posicionamientos de los sindicatos y de la propia Comisión Europea. Como quiera que estos movimientos, en general, excepto en el caso mencionado de los taxistas, no han tenido mucha potencia, las respuestas de los Gobiernos también han sido tibias. En tercer lugar, a partir del análisis de experiencias de regulación en tres países, podemos concluir que la regulación por parte del Estado se ha concentrado en aspectos relacionados con las reglas que afectan a la competencia, derechos de información y otros aspectos de gestión de acceso a internet, pero ha dado menos importancia a la regulación del empleo.

Con el objetivo de recabar elementos utilizables también en España, veamos las conclusiones que podemos inferir de los tres casos estudiados - Alemania, Francia, Reino Unido ${ }^{8}$ - por lo que se refiere al empleo y al mercado de trabajo. Alemania tiene una gran tradición reguladora y de respeto a los derechos de los diversos colectivos de trabajadores, que se traduce principalmente en la negociación colectiva por sector y territorio (el land). Ello puede explicar que en el enfrentamiento entre Uber y los taxistas se haya regulado a favor de estos últimos; en este caso tuvieron lugar numerosas demandas judiciales, en buena parte falladas a favor de los taxistas hasta que, en marzo de 2016, el tribunal regional de Frankfurt confirma la prohibición de Uber Pop en toda Alemania por no estar sujeta a la regulación del transporte público ${ }^{9}$. No obstante, los trabajadores independientes de las plataformas siguen siendo considerados como trabajadores autónomos, aunque el Ministerio de Trabajo y Asuntos Sociales ha señalado en un informe de 2016 (BMAS, 2016) que podría estudiarse su asimilación a los trabajadores a domicilio. El mismo ministerio, en el libro blanco del trabajo, 2016, invita a los agentes sociales a incluir temas como la negociación colectiva y los planes de pensiones para los trabajadores de las plataformas. También se han desarrollado algunas iniciativas de autorregulación a través de la negociación colectiva, y el sindicato IG Metal está llevando a cabo una campaña para regular salario, horario y protección social de estos trabajadores. Es decir, por ahora estamos en un estadio de intentos de regulación, más bien voluntarios por lo que respecta a las empresas.

En Francia parecen haberse dado pasos más decididos. La Ley El Komri $(2016)^{10}$ exige que las plataformas ofrezcan a los nuevos trabajadores un seguro por accidentes, derechos de formación, derecho de afiliación y derecho a acciones colectivas. De este último aspecto se puede esperar algún movimiento colectivo, aunque hasta ahora los sindicatos no han conseguido sentar a los empresarios de las plataformas para un diálogo social. Para algunos investigadores, la ley ha hecho avanzar poco los derechos en la práctica. La razón estaría en que la propia inspección de trabajo es poco partidaria de introducir un nuevo estatus laboral para los trabajadores de las plataformas (Lenaerts et al., 2017), mientras que los sindicatos son débiles como para conseguir que los derechos de los asalariados se apliquen a estos "trabajadores independientes". Por ello en Francia, al contrario que en Alemania, podemos hablar de regulación, pero con aplicación soft. Ello explica el desarrollo paralelo de iniciativas de diálogo social ${ }^{11}$.

En el caso del Reino Unido se refleja el predominante enfoque liberal de la economía que, en términos de interés de los últimos Gobiernos, se traduce en escasa sensibilidad por los derechos laborales de estos trabajadores. Con todo, no han podido dar la espalda a la nueva realidad. El Gobierno May impulsa el Informe Taylor $2017^{12}$, que busca fórmulas para adecuar la legislación laboral vigente a una situación tan cambiante. También

Hemos utilizado el caso de Reino Unido, formalmente ya fuera de la UE, porque es un marco regulatorio especifico que durante años influyó en la regulación proveniente de la UE.

9 Algo semejante tiene lugar en 2019 en el área metropolitana de Barcelona, en este caso como respuesta de la Administración a una larga huelga de taxistas.

10 Loi no 2016-1088 de 8 agosto de 2016 relativa al trabajo, a la modernización del dialogo social y la estabilidad de los itinerarios profesionales, llamada loi Travail o loi El Khomri, es una ley adoptada en Francia en 2016 a iniciativa del ministro de Trabajo Myriam El Khomri en nombre del Gobierno de Valls.

11 France Stratégie, Sharers \& Workers e IGAS lanzaron conjuntamente una iniciativa participativa en diciembre de 2016 que reúne a plataformas digitales, interlocutores sociales y expertos para profundizar en el Informe IGAS sobre plataformas (Chagny et al., 2017).

12 En julio de 2017 se publicó el informe sobre Prácticas Modernas y Buen Trabajo, encargado por el Gobierno británico al antiguo asesor de Tony Blair y experto politólogo, Matthew Taylor. 
se crean algunas comisiones parlamentarias al respecto, pero las consecuencias prácticas son escasas. Por tal motivo los sindicatos han animado a utilizar la vía judicial, con cierto éxito; el ejemplo más claro ha sido conseguir que los conductores de Uber sean considerados trabajadores dependientes a todos los efectos. Los sindicatos tampoco han conseguido, en este caso, abrir un diálogo social serio.

En resumen, así como las plataformas han aprovechado vacíos legales, también colectivos de trabajadores independientes han obtenido sentencias judiciales favorables, pero no siempre, lo cual es indicador de algunos aspectos poco claros en el ordenamiento legal. Los Gobiernos muestran poca sensibilidad a regular derechos en un mercado de trabajo que está cambiando, con excepciones concretas en Alemania y Francia. Probablemente, también los sindicatos deberían buscar nuevas formas organizativas y de actuación para consolidar la fuerza de los "trabajadores independientes", en la máxima unidad y comprensión posibles con los asalariados comunes.

$\mathrm{Al}$ adoptar medidas políticas, los Gobiernos nacionales se han centrado especialmente en temas relacionados con la protección social, los impuestos y la competencia, mientras que aspectos relacionados con la regulación laboral o la negociación colectiva han recibido mucha menos atención. Así pues, en ninguno de los países examinados se ha desarrollado un marco legal específico relacionado con la economía de plataforma. Las medidas que se han introducido parecen ser bastante ad hoc, sin adecuarse al carácter estructural de las transformaciones provocadas por la economía digital. Además, los Gobiernos generalmente intentan aplicar la legislación y la regulación existentes a la economía de plataforma, con resultados ambiguos, porque no se ha asumido que la economía digital es el nervio central de la nueva economía. La experiencia de trabajar desde casa, que ha provocado la pandemia del Covid-19, puede hacer que empresas, sindicatos, trabajadores e instituciones sean más conscientes de la nueva realidad.

Con todo, es importante resaltar la existencia de diferencias significativas entre países en el objeto de la regulación. No cabe despreciar las vías diversas que los diferentes modelos sociales y económicos han consolidado en los países europeos, pero, en nuestra opinión, la revolución digital es una buena ocasión para que la UE profundice en algunas políticas comunes a los 27 países con el objetivo de garantizar que los cambios tecnológicos se den con las mejores consecuencias posibles para quienes buscan un empleo.

\section{Conclusiones}

La principal conclusión de esta investigación es que hasta ahora se han aprovechado poco las posibilidades de la economía digital para mejorar el empleo. Las razones son falta de inversión en $\mathrm{I}+\mathrm{D}+\mathrm{i}$, actitudes poco arriesgadas de las empresas, baja formación en habilidades digitales y excesivo peso de sectores poco digitalizables. Pero hay puntos fuertes que apuntan un cambio, señalan los encuestados: adaptabilidad de los jóvenes, buena formación en ingenierías, buena red de conexiones digitales, atractivo inversor del país.

Una gran mayoría de los entrevistados cree que la economía digital creará mucho empleo, aunque el riesgo es que dicho empleo sea de poca calidad (en salarios, en posibilidades de promoción...). Ello provocará una dualización que puede desembocar en emigración de personas bien preparadas (en ingeniería, medicina, medioambiente, etc.), al tiempo que nuestra economía atrae inmigración poco cualificada.

Además de las habilidades STEM, las habilidades transversales más necesarias para el futuro de la economía en España, señalan los encuestados, son la creatividad, la capacidad de resolución de problemas complejos, la flexibilidad cognitiva y el trabajo en grupo. Para conseguirlas debe jugar un papel importante la formación, pero también las oportunidades que ofrezcan las empresas. La educación inicial y la formación a lo largo de la vida, esta última concebida como un derecho, deben poner el acento en las habilidades STEM, pero casi al mismo nivel en potenciar las habilidades de cada individuo, piensan los entrevistados, dado que de ahí nacen las habilidades transversales.

Por todo ello, las políticas que la Administración lleve a cabo, a ser posible junto con las empresas, son esenciales. Se ha de invertir mucho más en $\mathrm{I}+\mathrm{D}+\mathrm{i}$, pues seguimos estando muy abajo en el ranking de la UE. Se requiere una clara decantación por un modelo energético en el que las energías renovables sean la base, volviendo a niveles que ya se tenían en 2008. También en el apoyo a las PYMES es fundamental el papel del Estado, pero no solo facilitando el crédito, sino también la formación de los propios empresarios, y que estos hagan contrataciones con empleo de calidad.

En otro orden de cosas, una gran mayoría cree que se debe regular el nuevo empleo, en especial en las plataformas, con el objetivo de que las garantías laborales y el derecho a la negociación sean respetados ${ }^{13}$. $\mathrm{Y}$, ante la pérdida de empleos en ciertos sectores, la Administración debe impulsar mecanismos como la reducción del tiempo de trabajo que haga crecer el número de empleos, y el ingreso mínimo vital, condicionado a la formación o al empleo con formación para poder volver a reinsertarse.

\footnotetext{
13 Con fecha 25/09/2020, el Tribunal Supremo ha dictado una sentencia histórica por la que considera que los riders son trabajadores asalariados, unificando de este modo los diversos criterios que habían expresado hasta el momento los tribunales españoles. Posteriormente, el 10/3/2021 el Gobierno y los agentes sociales han llegado a un acuerdo para reconocer la condición de asalariados para estos mismos trabajadores.
} 
La comparación con otros países pone de manifiesto que pueden predominar tres tipos de regulaciones: en Alemania, la negociación sectorial-territorial; en Francia, la regulación por ley, y en el Reino Unido, la intervención de los jueces a instancias de los trabajadores. Pero es común a todos ellos el hecho de que la calidad del empleo y el mantenimiento de los derechos laborales, en el proceso de esta revolución digital, aún no esté en el centro de la preocupación del sistema.

El Covid-19 ha sido un acelerador de algunos de los procesos que hemos señalado en la investigación, por lo que nos aporta algunas enseñanzas. La primera es que la digitalización de muchos empleos va a ser más rápida de lo que podíamos prever hace unos años, particularmente aquellos empleos que tienen una fuerte carga administrativa o estrictamente comunicativa. Ello puede provocar que muchas empresas configuren esos empleos con base en la vivienda del trabajador al menos algunos días por semana. El tiempo de trabajo, la no desconexión, el grado de responsabilidad y otras cuestiones serán aspectos que ocuparán el debate, puesto que cambiarán las condiciones de trabajo. La pandemia del Covid-19 habrá contribuido en forma notable a acelerar la digitalización de la economía. Más en particular, la necesidad ha demostrado que en poco tiempo muchos podían estar disponibles para teletrabajar, pero que dicho teletrabajo podía darse en condiciones poco deseables. Por tanto, se requiere regular esta nueva modalidad y probablemente propiciar que los trabajadores/as puedan decantarse por compaginarlo con el trabajo presencial ${ }^{14}$. De lo contrario, el riesgo puede ser una fuerte individualización de las relaciones laborales que encierre a cada individuo en su mundo laboral, y le haga perder la capacidad de socialización que significa la defensa colectiva de las condiciones de trabajo.

La segunda enseñanza es que muchas personas han aprendido a utilizar ciertas herramientas digitales que anteriormente no tomaban en consideración, o lo hacían con poca frecuencia y dificultades, y para las que se han capacitado rápidamente. Ello pone de manifiesto que tenemos muchas más capacidades para adquirir nuevas habilidades en este terreno de lo que a priori habríamos podido pensar. Una tercera enseñanza nos sitúa en el plano de las dotaciones en infraestructuras y acceso a internet, hoy por hoy muy desiguales según el territorio y la vivienda, aspectos que las empresas e instituciones que apuesten por el teletrabajo deberán atender.

Como cuarta enseñanza, la pandemia ha dejado claro que se requiere mayor inversión en $\mathrm{I}+\mathrm{D}+\mathrm{i}$, también en sectores como la sanidad y la asistencia social, y en general en las PYMES; y que la mejora de dicha inversión en las empresas habría permitido que muchas pudieran haber seguido vendiendo telemáticamente, a pesar de tener sus persianas bajadas. También han quedado en evidencia las consecuencias de una globalización descontrolada que ha deslocalizado la industria con el único criterio de reducir los costes de producción, sin consideración del gravamen ecológico ni del riesgo de quedar desabastecidos en unos momentos críticos de productos esenciales para vivir o para afrontar una pandemia.

Una quinta enseñanza tiene que ver con el papel del Estado, no solo en la tutela de la sanidad pública y de los cuidados sociosanitarios, también en el mantenimiento de la actividad y el empleo. Los meses que seguirán al gran embate de la pandemia pondrán de manifiesto que parte del tejido económico y del empleo se hundirán si no hay un apoyo decidido del Estado, ya sea a través de avales a las empresas o a través de apoyo a los trabajadores, y la creación del ingreso mínimo vital es un claro ejemplo de este papel. Tan importante como esto es que el Estado ejerza un protagonismo determinante en la modernización de la estructura productiva que dependa lo menos posible del exterior en los productos y servicios esenciales, que fomente y aproveche al máximo la innovación tecnológica, pero en forma inclusiva, que respete el medio ambiente y que mantenga un cierto equilibrio entre sectores productivos y de servicios para evitar que desaparezca alguno de ellos por factores coyunturales. Quizá no necesitemos esperar más para convencernos de que ese mismo Estado es clave para prevenir las crisis, a través de regulaciones adecuadas y razonables. A este respecto cabe destacar la extraordinaria oportunidad que supone el Plan de Recuperación para Europa, junto con el instrumento económico temporal NextGenerationEU, cuyos objetivos son una recuperación económica que tenga en cuenta el reto tecnológico y el reto ambiental, pero que sea inclusiva y social ${ }^{15}$. Sobre la base de este plan, está previsto que España reciba transferencias y créditos por valor de 140.000 millones de euros a lo largo de los próximos años.

\section{Bibliografía}

Accenture y Mobile World Capital Barcelona (2017): Digital Economic Opportunity in Spain. How digitalization may boost the Spanish Economy. Disponible en: https://www.accenture.com/t00010101T000000Z_w_/es-es/_acnmedia/PDF-59/ Accenture-Strategy-Digital-Transformation.pdf [Consulta: 5 de mayo de 2020].

Adecco (2016): Informe Adecco sobre el futuro del trabajo en España. Disponible en: https://adecco.es/wp-content/ uploads/2017/11/informe_futuro_adecco.pdf [Consulta: 15 de mayo de 2020].

Allen, D. y C. Berg (2014): The sharing economy. How over-regulation could destroy an economic revolution, Institute of Public Affairs, Australia.

\footnotetext{
14 Con fecha 22/9/20, el Gobierno ha aprobado el Real Decreto-Ley 28/2020, de trabajo a distancia, que regula el trabajo que se realiza fuera de los establecimientos y centros habituales de la empresa, y en particular el teletrabajo.

15 Ver al respecto el Plan de Recuperación para Europa | Comisión Europea.
} 
Arntz, M., T. Gregory y U. Zierahn (2016): The Risk of Automation for Jobs in OECD Countries: A Comparative Analysis, OECD Social, Employment and Migration Working Papers, 189, Paris, OECD Publishing.

Berg, J. y V. De Stefano (2016): “Employment and regulation for clickworkers”, en M. Neufeind, J. O’Reilly y F. Ranft, eds., Work in the digital age: challenges of the fourth industrial revolution, London, Rowman \& Littlefield International, pp. 175-184.

BMAS (Bundesministerium für Arbeit und Soziales) (2016): Weißbuch. Arbeiten 4.0. Disponible en: http://www.bmas.de/DE/ Service/Medien/Publikationen/a883-weissbuch.html [Consulta: 12 de mayo de 2020].

CCOO Industria (2017): La Digitalización y la Industria 4.0. Impacto industrial y laboral. Disponible en: https://industria.ccoo. es/4290fc51a369\%207f785ba14fce86528e10000060.pdf [Consulta: 5 de mayo de 2020].

CEOE (2016): Plan Digital 2020: La digitalización de la sociedad española. Disponible en: http://contenidos.ceoe.es/CEOE/var/ pool/pdf/publications_docs-file-334-plan-digital-2020-la-digitalizacion-de-la-sociedadespanola.pdf [Consulta: 5 de mayo de 2020].

CES (2017): La digitalización de la economía, Informe 03/2017, Madrid, Consejo Económico y Social de España. Disponible en: http://www.ces.es/documents/10180/4509980/Inf0317.pdf [Consulta: 14 de mayo de 2020].

Chagny, O., C. Jolly, A. Naboulet, N. Amar y L. C. Viossat (2017): Dialogue social et protection sociale dans l'économie des plateformes: enjeux et pistes d'actions, France Strategie.

Coady, D., I. Parry, L. Sears y B. Shang (2017): "How large are global fossil fuel subsidies?", World development, 91, pp. 11-27.

Comisión Europea (2010a): Comunicación de la Comisión al Parlamento Europeo, al Consejo, al Comité Económico y Social Europeo y al Comité de las Regiones. Una Agenda Digital para Europa. Disponible en: https://eur-lex.europa.eu/legalcontent/es/ALL/?uri=CELEX:52010DC0245 [Consulta: 23 de abril de 2020].

Comisión Europea (2010b): Estrategia Europea 2020. Disponible en: https://eur-lex.europa.eu/legal-content/ES/ TXT/?uri=LEGISSUM\%3Aem0028 [Consulta: 13 de abril de 2020].

Comisión Europea (2015): Comunicación de la Comisión al Parlamento Europeo, al Consejo, al Comité Económico y Social Europeo y al Comité de las Regiones. Una Estrategia para el Mercado Único Digital de Europa. Disponible en: https://eurlex.europa.eu/legal-content/ES/ALL/?uri=celex\%3A52015DC0192 [Consulta: 1 abril de 2020].

De Stefano, V. (2016): The rise of the "just-in-time workforce": On-demand work, crowdwork and labour protection in the "gigeconomy", ILO, Conditions of work and employment series, 71. Disponible en: http://www.ilo.org/wcmsp5/groups/public/--ed_protect/---protrav/---travail/documents/publication/wcms_443267.pdf [Consulta: 20 de abril de 2020].

Dittrich, P. J. (2018): Online pltatforms and how to regulate them: an EU overview. Disponible en: https://www.delorscentre. eu/en/publications/detail/publication/online-platforms-and-how-to-regulate-them-an-eu-overview/ [Consulta: 13 de mayo de 2020].

Doménech, R., J. R. García, M. Montañez y A. Neut (2018): How vulnerable is Spanish employment to the digital revolution? BBVA research working paper. Disponible en: https://www.bbvaresearch.com/wp-content/uploads/2018/03/How-vulnerableis-Spanish-employment-to-the-digital-revolution.pdf [Consulta: 1 de abril de 2020].

Drahokoupil, J. y B. Fabo (2016): The Platform economy and the disruption of the employment relationship, ETUI Policy Brief. Disponible en: https://www.etui.org/Publications2/Policy-Briefs/European-Economic-Employment-and-Social-Policy/Theplatform-economy-and-the-disruption-of-the-employment-relationship [Consulta: 6 de abril de 2020].

Eurofound (2018a): Automation, digitalisation and platforms: Implications for work and employment, Luxembourg, Publications Office of the European Union. Disponible en: https://www.eurofound.europa.eu/publications/report/2018/automationdigitisation-and-platforms-implications-for-work-and-employment [Consulta: 16 de abril de 2020].

Eurofound (2018b): Employment and working conditions of selected types of platform work, Luxembourg, Publications Office of the European Union. Disponible en: https:/www.eurofound.europa.eu/publications/report/2018/employment-and-workingconditions-of-selected-types-of-platform-work [Consulta: 16 de abril de 2020].

Eurofound (2019): Technology scenario: Employment implications of radical automation, Luxembourg, Publications Office of the European Union. Disponible en: https:/www.eurofound.europa.eu/sites/default/files/ef_publication/field_ef_document/ fomeef18009en.pdf [Consulta: 23 de abril de 2020].

European Commission (2019): Report of the High Level Expert Group on the Impact of the Digital Transformation on EU Labour Markets, Luxembourg, Publications Office of the European Union. Doi: 10.2759/586795.

European Commission (2020): The Digital Economy and Society Index (DESI). Disponible en: https://ec.europa.eu/digital-singlemarket/en/desi [Consulta: 16 de mayo de 2020].

Frey, C. B. y M. Osborne (2015): Technology at Work: The Future of Innovation and Employment, Oxford, University of Oxford.

IRENA (International Renewable Energy Agency) (2017): Renewable capacity statistics 2017. Disponible en: https://irena.org/ publications/2017/Mar/Renewable-Capacity-Statistics-2017 [Consulta: 17 de abril de 2020].

Lenaerts, K., M. Beblavy y Z. Kilhoffer (2017): “Government Responses to the Platform Economy: Where do we stand?”, CEPS Policy Insight. Disponible en: https:/www.ceps.eu/ceps-publications/government-responses-platform-economy-where-dowe-stand/ [Consulta: 19 de abril de 2020].

Lladós, J. (2018): "La transformación del empleo en España derivada de la automatización y la inteligencia”, en F. Miguélez, coord., La revolución digital en España, Impactos y retos sobre el mercado de trabajo y el bienestar, pp. 85-121. Disponible en: https://ddd.uab.cat/record/190329 [Consulta: 25 de mayo de 2020].

Lope, A. (2018): "Limitaciones de la formación a las personas ocupadas para adecuar sus capacidades a los cambios en el empleo", en F. Miguélez, coord., La revolución digital en España. Impactos y retos sobre el mercado de trabajo y el bienestar, pp. 243-283. Disponible en: https://ddd.uab.cat/record/190326 [Consulta: 25 de mayo de 2020].

López-Sintas, J., G. Souto y S. F. Van Hemmen (2018): "Innovación digital y transformación de las organizaciones: implicaciones sociales y laborales", en F. Miguélez, coord., La revolución digital en España. Impactos y retos sobre el mercado de trabajo y el bienestar, pp. 49-83. Disponible en: https://ddd.uab.cat/record/190320 [Consulta: 25 de mayo de 2020].

Maselli, I., K. Lenaerts y M. Beblavy (2016): "Five things we need to know about the collaborative economy", CEPS Essay, 21. Disponible en: https://www.ceps.eu/ceps-publications/five-things-we-need-know-about-demand-economy/ [Consulta: 19 de abril de 2020]. 
Mazzucato, M. y G. Semieniuk (2017): "Public financing of innovation: new questions", Oxford Review of Economic Policy, 33(1), pp. 24-48.

McKinsey Global Institute (2017): Jobs lost, jobs gained: What the future of work will mean for jobs, skills, and wages. Disponible en: https://www.mckinsey.com/featured-insights/future-of-organizations-and-work/jobs-lost-jobs-gained-what-the-futureof-work-will-mean-for-jobs-skills-and-wages [Consulta: 2 de junio de 2020].

Miguélez, F. (coord.), R. Alós y O. Molina (2019): Economía Digital y Políticas de Empleo. Disponible en: https://ddd.uab.cat/ record/205104 [Consulta: 11 de mayo de 2020].

Ministerio de Industria, Energía y Turismo (2013): Agenda Digital para España. Disponible en: https://www.lamoncloa.gob.es/ documents gendadigital150213.pdf [Consulta: 5 de abril de 2020].

Navarro, S. (2018): "Descentralización de las políticas activas de empleo", en F. Miguélez, coord., La revolución digital en España. Impactos y retos sobre el mercado de trabajo y el bienestar, pp. 285-311. Disponible en: https://ddd.uab.cat/ record/190327 [Consulta: 15 de mayo de 2020].

Nübler, I. (2016): New technologies: A jobless future or golden age of job creation? Geneva, International Labour Office.

Organización Internacional del Trabajo (2019): Trabajar para un futuro más prometedor, Ginebra, OIT. Disponible en: https:// www.ilo.org/global/publications/books/WCMS_662442/lang--es/index.htm [Consulta: 26 de marzo de 2020].

Pesole, A., C. Urzi Brancati, E. Fernández Macías, F. Biagi e I. González Vázquez (2018): Platform Workers in Europe, Luxembourg, Publications Office of the European Union. Doi:10.2760/742789 [Consulta: 2 de mayo de 2020].

Planas, J. (2018): "El futuro de la relación entre educación y trabajo", en F. Miguélez, coord., La revolución digital en España. Impactos y retos sobre el mercado de trabajo y el bienestar, pp. 159-187. Disponible en: https://ddd.uab.cat/record/190323 [Consulta: 25 de mayo de 2020].

Powell, W.W. y K. Snellman (2004): “The knowledge economy”, Annual Review of Sociology, 30: 199-220. Doi: 10.1146/ annurev.soc.29.010202.100037.

Prieto, C. y M. Alaluf (2018): "La renta básica universal contra el Estado Social”, Gaceta Sindical: reflexión y debate, 31, pp. 89-100.

PWC (2018): Will robots really steal our jobs. An international analysis of the potential long term impact of automation. Disponible en: https://www.pwc.com/hu/hu/kiadvanyok/assets/pdf/impact_of_automation_on_jobs.pdf [Consulta: 5 de mayo de 2020].

Rauch, D. E. y D. Schleicher (2015): "Like Uber, but for local government law: The future of local regulation of the 'sharing economy", George Mason University Law and Economics Research Paper Series, 15-01. Disponible en: https://papers.ssrn. com/sol3/papers.cfm?abstract_id=2549919 [Consulta: 15 de mayo de 2020].

Rocha, F. y L. de la Fuente (2018): The Social Dialogue in the face of digitalisation in Spain. An emerging and fragmented landscape, DIRESOC. Disponible en: http://1mayo.ccoo.es/fd26563df6fb4f5ad08fd2cc8744b24b000001.pdf [Consulta: 20 de abril de 2020].

Sarasa, S. (2018): “Garantía de ingresos mínimos y empleo”, en F. Miguélez, coord., La revolución digital en España, Impactos y retos sobre el mercado de trabajo y el bienestar, pp. 215-241. Disponible en: https://ddd.uab.cat/record/190325 [Consulta: 25 de mayo de 2020].

Schwab, K. (2016): La cuarta revolución industrial, Ginebra, Foro Económico Mundial, Debate.

Soete, L. (2018): “Destructive Creation. Explaining the productivity paradox in the digital age”, en M. Neufeind, J. O'Reilly y F. Ranft, eds., Work in the digital age: challenges of the fourth industrial revolution, London, Rowman \& Littlefield International, pp. 29-46.

Tapscott, D. (1996): The digital economy: Promise and peril in the age of networked intelligence (Vol. 1), New York, McGrawHill.

Todolí Signes, A. (2015): “El impacto de la ‘uber economy’ en las relaciones laborales: los efectos de las plataformas virtuales en el contrato de trabajo", IUSLabor, 3: 1-25.

UGT (2018): Impacto de la digitalización en el empleo en España, Madrid, Secretaría de política sindical. 